\title{
Sistem Pemantau Kelembapan Tanah Akurat dengan Protokol Zigbee IEEE 802.15.4 pada Platform M2M OpenMTC
}

\author{
Accurate Soil Moisture Monitoring System with Zigbee IEEE 802.15.4 on \\ OpenMTC M2M Platform
}

Putu Agus Fredy, Maman Abdurohman*)

Program Studi Informatika, Fakultas Informatika, Universitas Telkom Jl. Telekomunikasi No. 1, Dayeuhkolot, Bandung, Jawa Barat 40257

\begin{abstract}
Cara sitasi: P. A. Fredy and M. Abdurohman, "Sistem Pemantau Kelembapan Tanah Akurat dengan Protokol Zigbee IEEE 802.15.4 pada Platform M2M OpenMTC,” Jurnal Teknologi dan Sistem Komputer, vol. 6, no. 4, pp. 139-145, Oct. 2018. doi: 10.14710/jtsiskom.6.4.2018.139-145, [Online].
\end{abstract}

\begin{abstract}
This paper presents a study on an accurate soil moisture monitoring system based on its humidity from 9 sensor nodes using wireless sensor network (WSN) and M2M platform. The system used IEEE 802.15.4 (Zigbee) protocol. The system was connected to the application via the OpenMTC M2M platform. This monitoring system can measure soil moisture accurately and provide soil water content status on the application. The system was effective in measuring soil moisture at a distance of 0-25 meters where there was a barrier between gateway and sensor, and at a distance of 0-50 meter in line of sight. The position of the sensors that are within 3 meters of each other and the depth of each sensor $3 \mathrm{~cm}$ can measure soil moisture properly.
\end{abstract}

Keywords - wireless sensor network; soil moisture; M2M platform; OpenMTC; surface soil moisture

\begin{abstract}
Abstrak - Paper ini mengusulkan sebuah sistem pemantauan kadar air tanah yang akurat secara nirkabel berdasarkan kelembapannya dari 9 titik sensor dengan menggunakan jaringan sensor nirkabel (JSN) dan platform M2M. Protokol yang digunakan adalah IEEE 802.15.4 (Zigbee). Sistem ini terhubung dengan aplikasi melalui platform M2M OpenMTC. Sistem pemantau ini dapat mendeteksi kelembapan tanah secara akurat dan memberikan status kondisi kadar air tanah. Sistem ini efektif dalam mengamati kelembapan tanah pada jarak 0-25 meter dalam kondisi terdapat penghalang antara sensor dan gateway, dan pada jarak 0-50 meter dalam kondisi tidak ada penghalang. Posisi sensor-sensor yang saling berjarak 3 meter dan kedalaman tiap sensor 3 cm dapat mengukur kadar air tanah dengan baik.
\end{abstract}

Kata kunci - jaringan sensor nirkabel; pemantau kelembapan tanah; platform M2M; OpenMTC; kadar air tanah permukaan

\footnotetext{
${ }^{*}$ Penulis korespondensi (Maman Abdurohman) Email: abdurohman@telkomuniversity.ac.id
}

\section{Pendahuluan}

Tanah merupakan media penting agar tanaman dapat tumbuh secara optimal. Air dalam tanah sangat dibutuhkan oleh tanaman sebagai pendorong proses respirasi dan pertumbuhan tanaman. Kekurangan atau kelebihan air tanah akan menyebabkan tanaman tumbuh kurang optimal sehingga dibutuhkan sistem yang dapat memantau kadar-air dalam tanah secara otomatis. Pengukuran kelembapan tanah dapat dilakukan dengan mengukur perbedaan berat tanah. Metode lainnya adalah dengan mengukur hambatan listrik di dalam tanah [1]. Metode tersebut akurasinya cukup tinggi, namun dibutuhkan upaya yang besar. Sebuah metode baru diperlukan untuk mengukuran perubahan kadar air tanah yang lebih efisien.

Teknologi komunikasi dapat dimanfaatkan untuk mengatasi hal tersebut, di antaranya jaringan sensor nirkabel (JSN), modul XBee, Arduino, dan platform machine-to-machine (M2M). JSN menghubungkan perangkat node sensor dan router secara ad-hoc dan mendukung komunikasi multi-hop [2] dengan perangkat pendukung transceiver, kontroler, memori dan sensor. Protokol komunikasi yang digunakan dalam JSN adalah Zigbee yang mengadopsi standar IEEE 802.15.4 untuk komunikasi jaringan area personal nirkabel kecepatan rendah (LR-WPAN) [3], [4].

Beragam aplikasi dikembangkan dengan JSN dan M2M menggunakan platform OpeMTC, di antaranya sistem deteksi kebocoran pipa air [5], sistem kota cerdas [6], dan deteksi polusi udara [7]. Aplikasi IoT pun telah dikembangkan untuk pertanian dan pertanahan [8]-[11]. Namun, sistem tersebut secara khusus digunakan untuk pemantauan sistem irigasi di lahan pertanian dan mengontrol kondisi tanah [8] dan manajemen pertanian [9]-[11]. Data dikirim, disimpan dan diolah dalam sebuah server web dengan protokol data yang tidak standar.

Paper ini mengusulkan sistem mendeteksi kelembapan tanah menggunakan JSN dengan protokol ZIGBEE/IEEE 802.15.4 yang menggunakan platform M2M OpenMTC. Sistem ini mampu mengukur kadar 


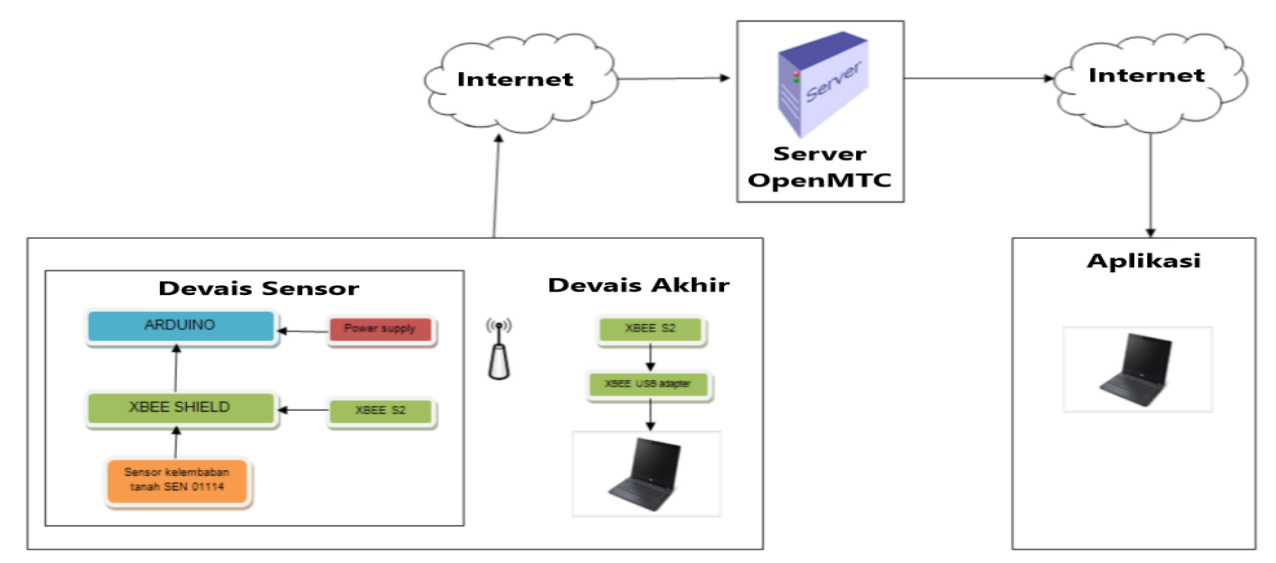

Gambar 1. Arsitektur sistem

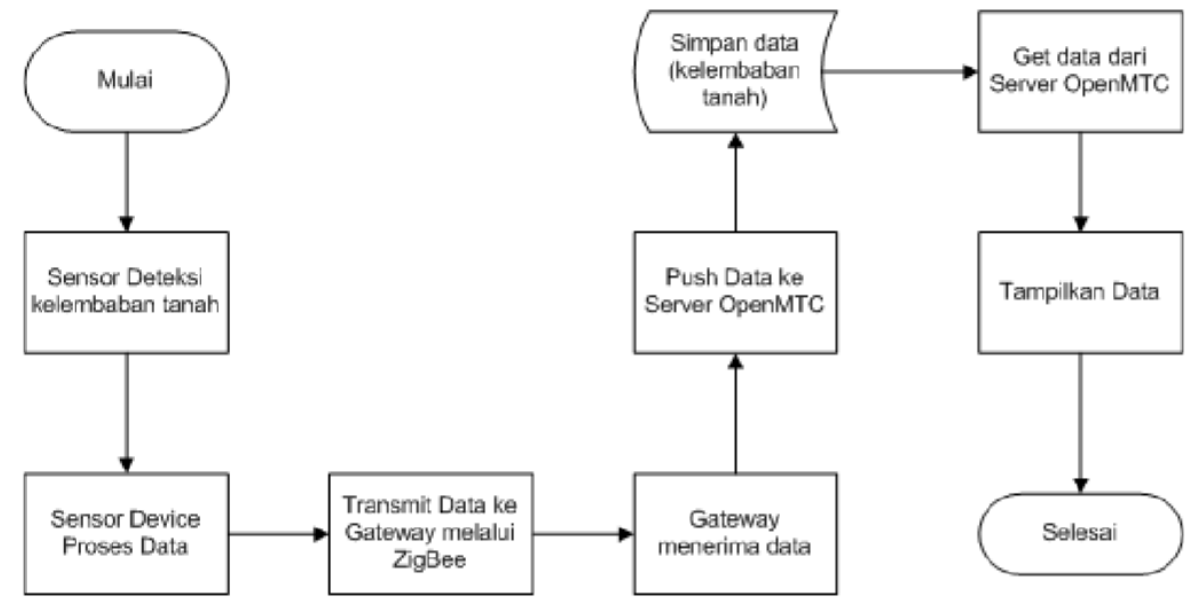

Gambar 2. Diagram alir sistem

air berdasarkan nilai kelembapan tanah yang akurat. Selain itu, sistem pemantauan ini dapat digunakan sebagai peringatan dini jika kadar air dalam tanah terlalu sedikit ataupun terlalu banyak.

\section{Metode Penelitian}

Sistem pendeteksian kelembapan dilakukan dengan menggunakan sensor kelembapan tanah yang terhubung dengan ADC mikrokontroler. Data nilai kadar air tanah ditransmisikan menggunakan protokol ZigBee/IEEE 802.15.4 ke XBee sebagai penerima. Pada sisi server, data diproses dan diteruskan ke server M2M OpenMTC yang terhubung dengan aplikasi.

Sistem yang dirancang memiliki kemampuan untuk mengukur kelembapan tanah, menggunakan modul komunikasi Xbee S2, memproses hasil, menampilkan status air tanah, mengirimkan data ke aplikasi melalui OpenMTC, dan menampilkan grafik hasil pemantauan kelembapan tanah. Komunikasi yang terjadi antar devais sensor dan devais akhir menggunakan ZigBee secara point-to-point. Devais sensor dan devais akhir dapat melakukan pengambilan dan pengiriman data secara periodik ke server OpenMTC serta menampilkan data dalam bentuk grafik, dan menghasilkan status kekurangan atau kelebihan air.
Sistem pemantauan kelembapan tanah terbagi menjadi tiga bagian yaitu devais sensor, platform OpenMTC, dan devais akhir (Gambar 1). Devais sensor terdiri dari soil moisture sensor (SEN 01114), Arduino Uno, XBee, Xbee shield dan catu daya. Devais sensor ini berfungsi mengambil data kelembapan tanah, mengolah nilainya dan mengirimkan data ke gateway menggunakan modul Xbee. Gateway pada devais akhir terdiri dari modul XBee dan berfungsi sebagai node koordinator dengan menerima data yang masuk ke dalam aplikasi dari device sensor melalui jaringan ZigBee. Pengiriman data secara periodik ke platform OpenMTC dilakukan dalam format JSON melalui jaringan internet menggunakan metode HTTP REST. Aplikasi pengguna dibangun menggunakan Java untuk mengirim dan mengambil data ke server OpenMTC secara periodik. Diagram alir sistem pemantauan kelembapan tanah ini ditunjukkan dalam Gambar 2.

Pengujian terbagi menjadi empat skenario pengujian, yaitu pengujian performansi sistem, pengujian nilai kelembapan tanah, pengujian letak optimal sensor, dan pengujian sistem peringatan. Pengujian performansi sistem bertujuan untuk mengetahui waktu respon sistem. Waktu respon menggunakan selisih waktu dari mulai saat data pertama diterima sampai selesai saat data berikutnya masuk ke 


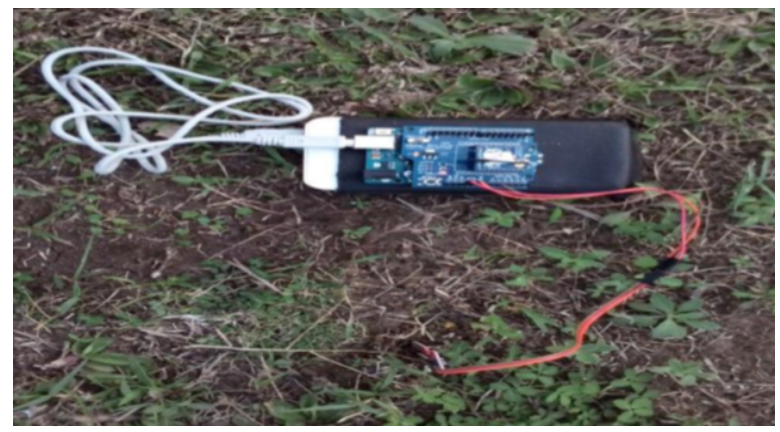

Gambar 3. Sensor di area pengujian

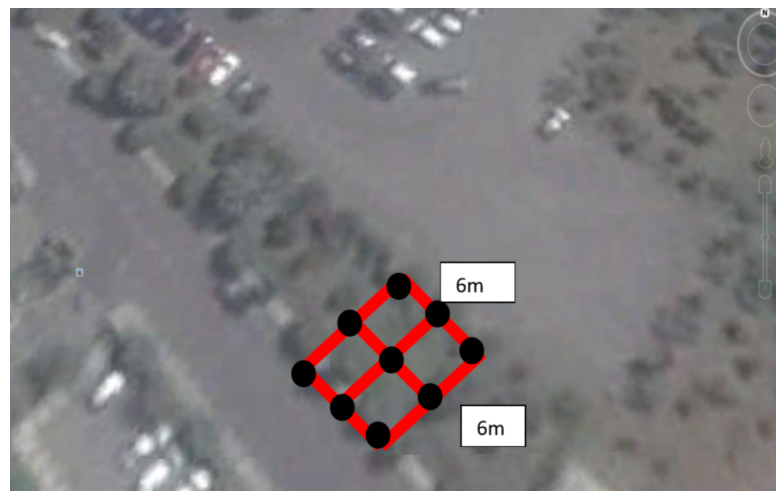

Gambar 4. Posisi peletakan sensor dalam bentuk grid

dalam aplikasi. Pengujian dilakukan dalam dua kondisi yaitu kondisi dengan adanya penghalang antara sensor dan gateway serta kondisi line of sight (LoS) tanpa halangan. Pengujian bertempat pada tanah di lingkungan Universitas Telkom (Gambar 3). Pengujian dilakukan secara bervariasi pada jarak $5 \mathrm{~m}, 10 \mathrm{~m}, 15 \mathrm{~m}$, $20 \mathrm{~m}$, 25m, dan 30m pada kondisi terdapat penghalang antara sensor dan gateway. Pada kondisi LoS, pengujian dilakukan pada jarak 10m, 20m, 30m, 40m, 50m, dan $60 \mathrm{~m}$.

Pengujian dimulai dari penempatan sensor pada jarak $5 \mathrm{~m}$ dari gateway dan rata-rata nilai waktu respon sistem dihitung pada jarak 5m, 10m, 15m, 20m, 25m, dan $30 \mathrm{~m}$ dengan kondisi adanya penghalang antara sensor dan gateway. Hasil dari data tersebut dibandingkan dengan pengujian pada jarak 10m, 20m, 30m, 40m, 50m, dan 60m dengan kondisi LoS untuk mengetahui performansi sistem yang dibangun.

Skenario pengujian nilai kelembapan tanah bertujuan untuk mengetahui perbedaan nilai kelembapan tanah yang dibaca oleh sensor pada kedalaman dan jenis tanah yang berbeda. Jenis tanah yang diuji adalah kering, lembab, dan basah dengan nilai kelembapan tanah kering sebesar 0-300, tanah lembab 301-600, dan tanah basah 601-900. Sensor diletakkan pada kedalaman $1 \mathrm{~cm}, 2 \mathrm{~cm}$, dan $3 \mathrm{~cm}$ untuk membaca nilai kelembapan di tanah kering, tanah lembab, dan tanah basah. Nilai yang terbaca pada sensor tiap kedalaman untuk masing-masing jenis tanah dibandingkan untuk menentukan kedalaman yang optimal sebagai acuan penempatan kedalaman sensor.

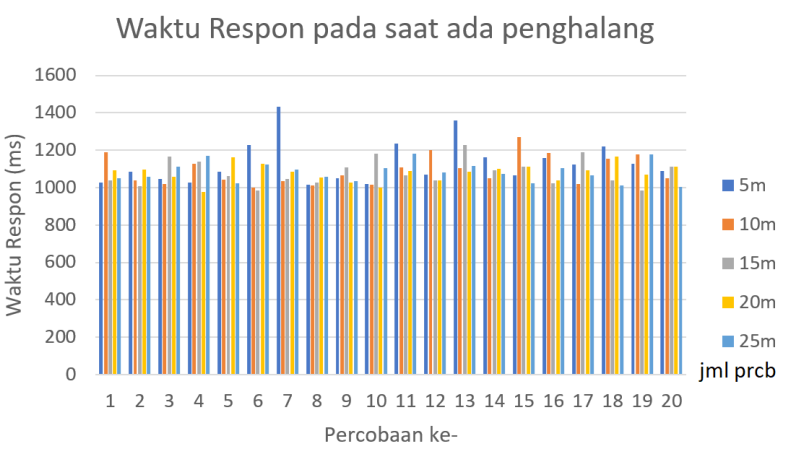

Gambar 5. Grafik pada kondisi terdapat penghalang

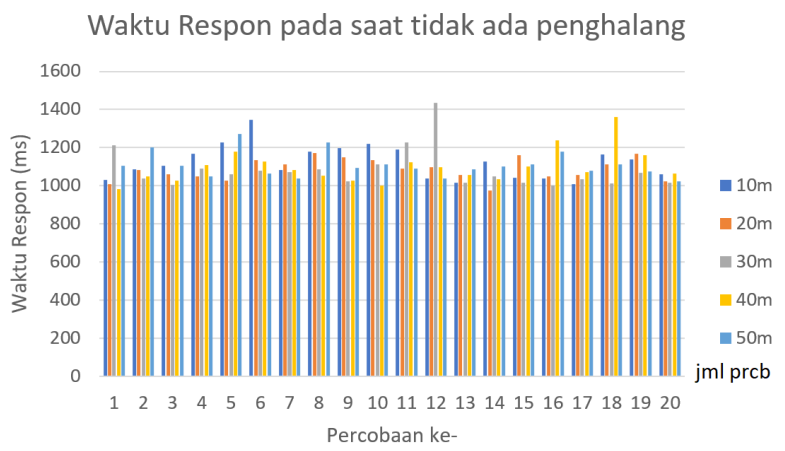

Gambar 6. Grafik data pada kondisi LoS

Skenario pengujian letak optimal penempatan sensor bertujuan untuk menentukan letak yang optimal bagi sensor sehingga data yang terbaca sensor dapat merepresentasikan nilai kelembapan tanah pada jarak yang telah ditentukan. Sensor diletakkan pada tanah denga posisi grid dengan jarak antar sensor adalah 3m (Gambar 4). Titik hitam merupakan posisi sensor 1 sampai 9 dan garis merah melambangkan luas tanah yang diukur, yaitu $6 \times 6 \mathrm{~m}^{2}$. Nilai kelembapan tanah pada masing-masing jarak dibaca oleh sensor. Nilai kelembapan dibaca dengan iterasi 20 dan dihitung ratarata setiap sensor untuk menentukan jenis tanah.

Skenario pengujian warning system bertujuan untuk mengetahui apakah sistem bisa menghasilkan pesan peringatan apabila tanah mengalami kekurangan atau kelebihan air. Sistem mengukur nilai kelembapan pada tanah kering dengan nilai kelembapan berada pada jangkauan 0-300. Sistem dipantau apakah bisa menampilkan pesan peringatan bahwa tanah kekurangan air atau tidak. Tanah kering kemudian disiram dengan air hingga nilai kelembapan yang terbaca oleh sensor menjadi di atas 600. Sistem dipantau apakah bisa menampilkan pesan tanah kelebihan air atau tidak.

\section{HASIl dAN PEMbahasan}

\section{A. Pengujian Performansi Sistem}

Pada skenario ini, waktu mulai sampai selesai untuk melakukan transmisi data dihitung dengan dua kondisi yaitu adanya penghalang antara sensor dengan gateway dan kondisi LoS. Masing-masing pengujian dilakukan sebanyak 20 kali. 
Tabel 1. Data pengukuran SEN400 dan SEN0111

\begin{tabular}{ccccc}
\hline \multirow{2}{*}{ Data ke- } & \multicolumn{2}{c}{ SEN 400 } & \multicolumn{2}{c}{ SEN 01114 } \\
\cline { 2 - 5 } & $\begin{array}{c}\text { Tanah } \\
\text { Kering }\end{array}$ & $\begin{array}{c}\text { Tanah } \\
\text { Basah }\end{array}$ & $\begin{array}{c}\text { Tanah } \\
\text { Kering }\end{array}$ & $\begin{array}{c}\text { Tanah } \\
\text { Basah }\end{array}$ \\
\hline 1 & 224 & 549 & 48 & 789 \\
2 & 223 & 542 & 44 & 779 \\
3 & 221 & 540 & 42 & 765 \\
4 & 224 & 537 & 43 & 754 \\
5 & 220 & 540 & 42 & 748 \\
6 & 224 & 540 & 43 & 747 \\
7 & 222 & 539 & 41 & 744 \\
8 & 221 & 543 & 42 & 744 \\
9 & 221 & 549 & 42 & 736 \\
10 & 223 & 549 & 43 & 735 \\
Rata-rata & 222 & 543 & 43 & 754 \\
\hline
\end{tabular}

Pada pengujian pertama dilakukan dengan adanya penghalang antara gateway dan sensor. Pengujian pertama dari jarak 5m sampai 30m, sebanyak 6 sensor dengan beda jarak $5 \mathrm{~m}$ dengan posisi devais sensor dengan gateway terhalang oleh tanaman dan beberapa pohon, tetapi transmisi data masih bisa dilakukan. Pada jarak 30m, transismi data tidak dapat dilakukan dengan kondisi packet loss. Hal tersebut terjadi karena devais sensor sudah tidak mampu mengirim data ke gateway karena jarak dan penghalang yang bertambah.

Pengujian pertama dengan penghalang mempunyai waktu respon sistem yang dibutuhkan rata-rata antara 1082 ms hingga 1131 ms (Gambar 5). Waktu respon rata-rata dari jarak $5 \mathrm{~m}$ sampai dengan $25 \mathrm{~m}$ tidak mengalami perubahan yang terlalu signifikan terhadap jarak. Faktor penghalang berupa pohon dan tanaman tidak menjadi masalah dalam proses transmisi data dari jarak $5 \mathrm{~m}$ hingga $25 \mathrm{~m}$. Jarak yang bertambah menjadi 30m dan bertambahnya penghalang menyebabkan terjadinya packet loss sehingga proses transmisi data tidak dapat dilakukan. Proses transimisi data hanya dapat terjadi pada jarak 0-25m dengan kondisi terdapat penghalang.

Pada kondisi LoS, waktu respon yang dibutuhkan oleh sistem berkisar antara 1082 ms sampai 1123 ms (Gambar 6). Perubahan jarak tidak memberi pengaruh yang signifikan terhadap waktu respon. Pada jarak $60 \mathrm{~m}$ terjadi packet loss yang menunjukkan devais sensor tidak dapat mengirim data ke gateway. Proses transmisi data hanya dapat terjadi pada jarak $0-50 \mathrm{~m}$ pada kondisi LoS. Jangkauan jarak sistem menggunakan Zigbee ini relatif dekat karena standar dan antarmuka Zigbee ditujukan untuk komunikasi area personal secara nirkabel [3], [4].

\section{B. Pengujian Kalibrasi Sensor dan Penentuan Kelembapan Tanah}

Pengujian ini bertujuan untuk kalibrasi sensor yang digunakan (SEN 01114) dengan sensor SEN VN400. Kalibrasi dilakukan untuk konversi nilai kelembapan tanah ke dalam bentuk persentase dengan nilai $0 \%$ apabila nilai kelembapan tanah sampai pada batas bawah tanah kering yang ditentukan dan 100\% apabila
Tabel 2. Kalibrasi sensor SEN400 dan SEN01114

\begin{tabular}{ccccc} 
& \multicolumn{3}{c}{ VN 400 } & \multicolumn{2}{c}{ SEN 01114 } \\
\cline { 2 - 5 } No & \% & Nilai Sensor & \% & Nilai Sensor \\
\hline 1 & 0 & 222 & 0 & 43 \\
2 & 10 & 253.8 & 10 & 115.6 \\
3 & 20 & 285.6 & 20 & 118.2 \\
4 & 30 & 317.4 & 30 & 260.8 \\
5 & 40 & 349.2 & 40 & 333.4 \\
6 & 50 & 381 & 50 & 406 \\
7 & 60 & 412.8 & 60 & 478.6 \\
8 & 70 & 444.6 & 70 & 551.2 \\
9 & 80 & 476.4 & 80 & 623.8 \\
10 & 90 & 508.2 & 90 & 696.4 \\
11 & 100 & 540 & 100 & 769 \\
\hline
\end{tabular}

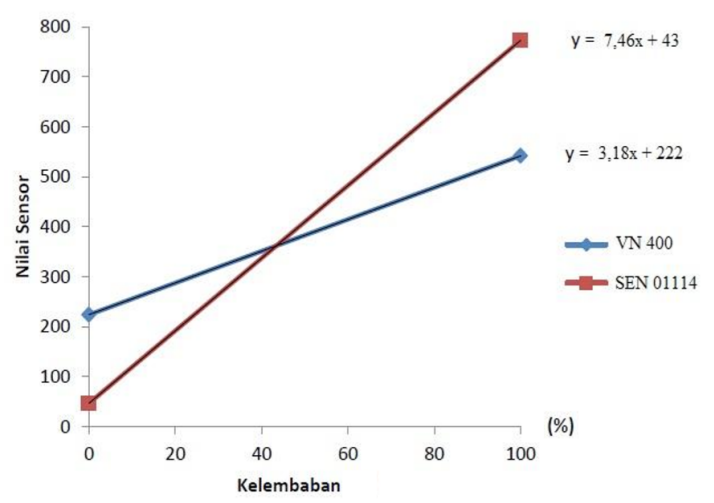

Gambar 7. Kurva linear hasil kalibrasi dengan median kelembaban SEN400 dan SEN01114

nilai kelembapan tanah sampai pada batas atas yang ditentukan.

Pengambilan data dilakukan sebanyak 10 buah data dalam waktu sekitar 1 menit. Persamaan linear dibuat berdasarkan dua median sebagai dasar nilai acuan. Kurva linear ini digunakan untuk kalibrasi nilai yang diperoleh dari pengukuran sensor. Hasil kalibrasi nilai sensor ini merepresentasikan nilai persentase kadar air tanah.

Luaran data sensor VN400 bertambah mengikuti nilai dari kelembapan tanah (Tabel 1). Tanah kering memiliki kelembapan lebih rendah daripada tanah jenuh dengan kadar air tinggi. Kondisi seperti ini sesuai dengan luaran sensor SN 01114, yaitu tanah kering memiliki nilai kelembapan yang lebih rendah dibanding tanah basah yang terbaca di monitor. Nilai sensor 222 dan 43 adalah median yang diperoleh dari data 10 luaran sensor tanah kering dengan tingkat kelembapan 0\%, sedangkan nilai sensor 542 dan 773 adalah median yang diperoleh dari data 10 luaran sensor tanah basah dengan tingkat kelembapan 100\%.

Kalibrasi nilai kelembapan kedua sensor diperoleh dari nilai median kedua sensor, yaitu berupa kurva linear dari dua data pada sumbu $\mathrm{x}$ dan y (Gambar 7). Variabel $\mathrm{x}$ menyatakan kelembapan dalam satuan persentase dan nilai y menyatakan nilai data luaran dari sensor. Persamaan linear dihasilkan dan digunakan sebagai acuan dalam kalibrasi nilai luaran sensor VN400 (Persamaan 1) dan SEN01114 (Persamaan 2). Persamaan tersebut digunakan untuk menentukan nilai 


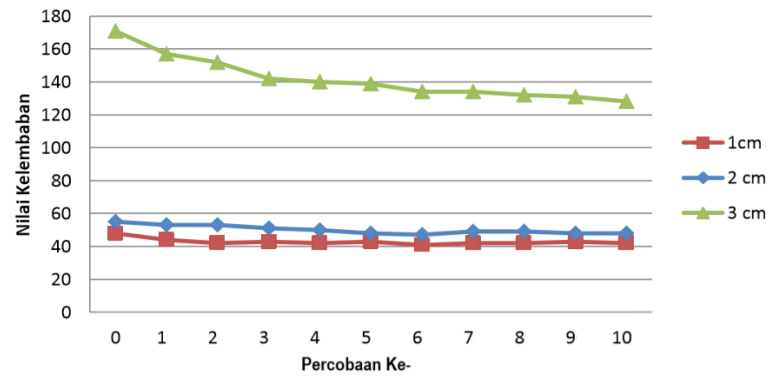

Gambar 8. Nilai kelembapan tiap kedalaman pada tanah kering

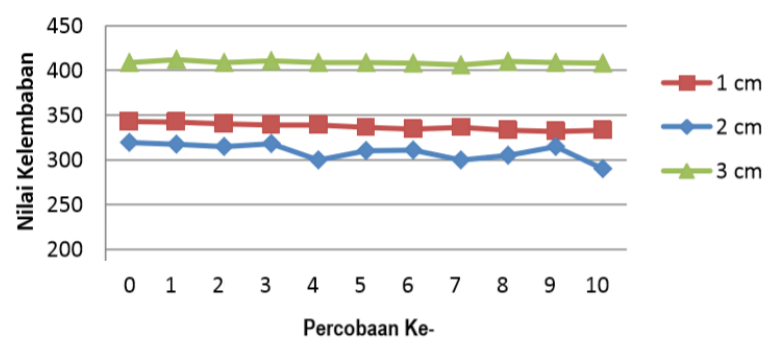

Gambar 9. Nilai kelembapan tiap kedalaman pada tanah lembap

kelembaban tanah dalam satuan persentase (Tabel 2). Nilai ini selanjutnya digunakan untuk menentukan status tanah.

$$
\begin{gathered}
y_{1}=3,18 x+222 \\
y_{2}=7,46 x+43
\end{gathered}
$$

\section{Pengujian Nilai Kelembapan Tanah pada Kedalaman dan Jenis Tanah yang Berbeda}

Pengujian ini bertujuan untuk mengukur perbedaan nilai kelembapan tanah yang dibaca oleh sensor pada kedalaman dan jenis tanah yang berbeda-beda. Jenis tanah yang digunakan adalah kering, lembap dan basah dengan nilai kelembapan tanah kering 0-300, tanah lembap 301-600, dan tanah basah 601-900.

Di tanah kering, nilai kelembapan tanah di kedalaman 1-2 cm berkisar antara 40-60, sedangkan dalam kedalaman $3 \mathrm{~cm}$ berkisar antara 120-170 (Gambar 8). Mulai kedalaman $3 \mathrm{~cm}$, perbedaan kelembapan semakin terlihat di tanah kering. Di tanah lembap dan basah, nilai kelembapan tanah proporsional terhadap kedalaman pengukuran (Gambar 9 dan Gambar 10). Kelembaban tanah yang semakin tinggi berdasarkan kedalaman tanah ini sesuai dengan [12]. Untuk tanah lembap, perbandingan kelembapan antara kedalaman $1 \mathrm{~cm}$ dan $2 \mathrm{~cm}$ tidak signifikan. Kelembapan tanah mulai berbeda di kedalaman $3 \mathrm{~cm}$ untuk ketiga tipe tanah tersebut.

\section{Pengujian Letak Optimal Penempatan Sensor}

Skenario ini bertujuan untuk menentukan letak yang optimal bagi sensor sehingga data yang terbaca sensor dapat merepresentasikan nilai kelembapan tanah pada

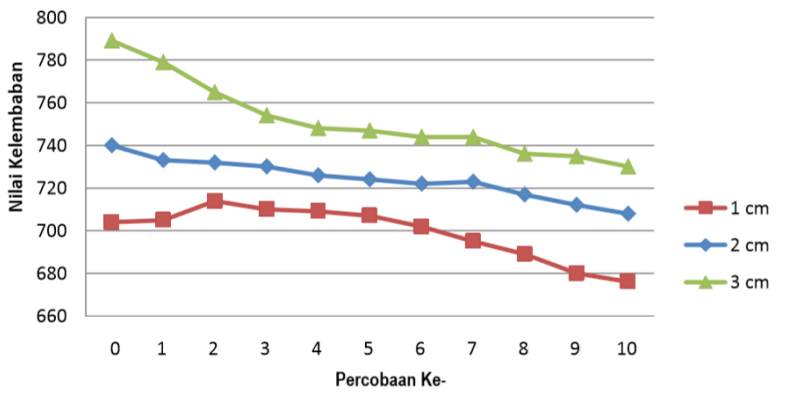

Gambar 10. Nilai kelembapan tiap kedalaman pada tanah basah

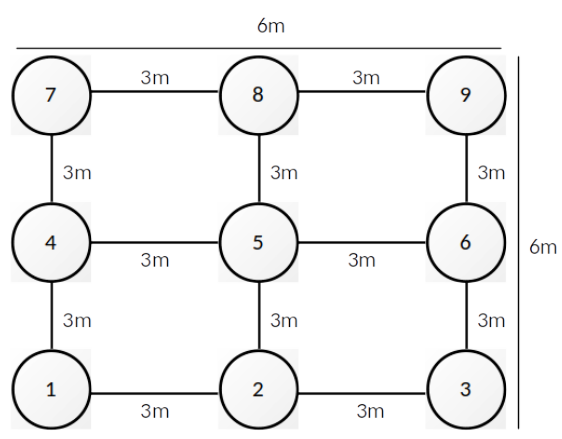

Gambar 11. Peletakkan sensor (1-9 adalah nomor sensor)

Tabel 3. Data kadar air berdasarkan nilai kelembapan

\begin{tabular}{|c|c|c|c|c|c|c|c|c|c|}
\hline Nilai & & & & Vilai & Sens & $r(\%$ & & & \\
\hline ke- & 1 & 2 & 3 & 4 & 5 & 6 & 7 & 8 & 9 \\
\hline 1 & 49 & 65,2 & 23,5 & 43,2 & 49 & 24,9 & & 54 & 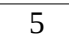 \\
\hline 2 & 48,9 & 65,1 & 23,8 & 43,2 & 49 & 24,5 & 41,5 & 54,8 & \\
\hline 3 & 4 & 65,2 & 23,4 & 43,1 & 49 & 24,9 & 41,9 & 53,7 & \\
\hline 4 & & . & 23,3 & 43 & 49 & 24,9 & 41,1 & 53,7 & \\
\hline 5 & 4 & 54,9 & 23,3 & 43,1 & 50,5 & 24,5 & 41,2 & 53,7 & \\
\hline 6 & 49,1 & 64,9 & 23,3 & 43,1 & 49 & 24,5 & 41,1 & 53,7 & \\
\hline 7 & 48,8 & 64,9 & 23,3 & 43,2 & 50,5 & 24,9 & 42 & 53,6 & 4,8 \\
\hline 8 & 48,8 & 64,9 & 23,1 & 43 & 50,5 & 24,9 & 41,2 & 53,7 & \\
\hline 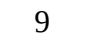 & 48,8 & 64,9 & 23,1 & 42,9 & 47,9 & 24,8 & 41,5 & 53,7 & - \\
\hline 10 & 48,8 & 64,8 & 23,1 & 42,6 & 49 & 24,8 & 41,5 & 53,6 & - \\
\hline 11 & 48,7 & 64,7 & 23 & 42,8 & 50,5 & 24,8 & 41,5 & 53 & 5 \\
\hline 12 & 48,7 & 64,7 & 23 & 42,8 & 50,5 & 24,7 & 41,9 & 53,6 & 5 \\
\hline 13 & 48,4 & 64,7 & 22,9 & 42,9 & 50,5 & 24,6 & 41,6 & 53,6 & 5 \\
\hline 14 & 48,2 & 64,7 & 22,9 & 42,9 & 49 & 24,7 & 41,6 & 53,6 & 5 \\
\hline 15 & 48,4 & 64,7 & 22,8 & 42,7 & 50,5 & 23,5 & 41,1 & 53,6 & 5 \\
\hline 16 & 48,7 & 64 & 22,8 & 42,7 & 51 & 23,5 & 41 & 53,5 & 4,8 \\
\hline 17 & 48,4 & 64,6 & 22,7 & 42,7 & 51 & 23,5 & 41,2 & 53,5 & 5 \\
\hline 18 & 48,4 & 64,4 & 22,4 & 42,7 & 49 & 23,5 & 41,1 & 53,5 & 5 \\
\hline 19 & 48,5 & 64,5 & 22,6 & 42,7 & 48,5 & 23,6 & 41,9 & 53,5 & 5 \\
\hline 20 & 48,4 & 64,5 & 22,6 & 42,6 & 49 & 23,6 & 41,1 & 53,2 & 5,1 \\
\hline Rerata & 48,7 & 64,8 & 23,1 & 42,9 & 49,7 & 24,5 & 41,4 & 53,7 & 4,99 \\
\hline
\end{tabular}
yang terukur dari Sensor 1-9

jarak yang telah ditentukan. Sensor-sensor akan diletakkan pada tanah dengan luas $6 \mathrm{~m}$ x $6 \mathrm{~m}$ dengan posisi grid. Jarak antar sensor adalah 3m (Gambar 11).

Pembacaan kelembapan dilakukan sebanyak 20 kali untuk tiap sensor dan nilainya dikonversikan menjadi kadar air menggunakan Persamaan 2. Dari area tersebut, terukur persentase kadar air yang menunjukkan kategori tanah lembap dan tanah kering (Tabel 3). Sensor 1, 2, 4, 


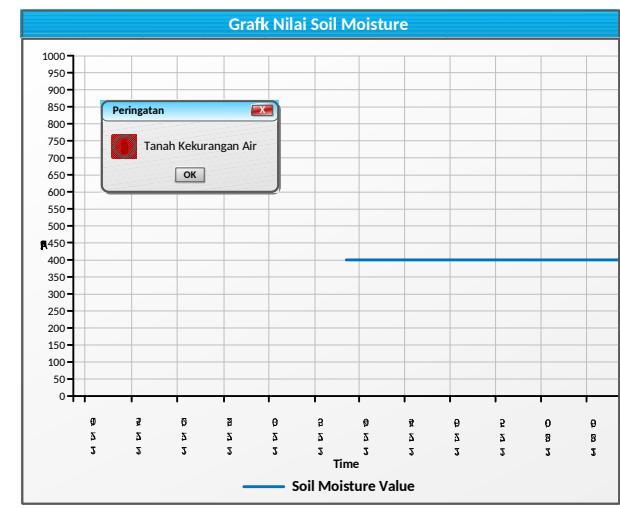

(a)

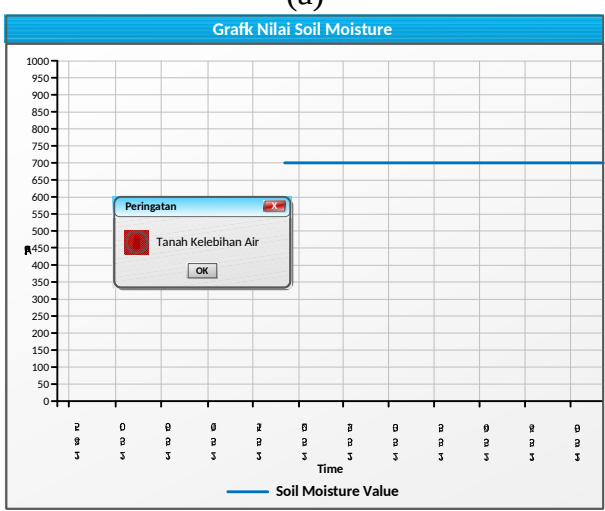

(b)

Gambar 12. Pesan peringatan aplikasi: a) kekurangan air dan b) keleihan air

5, 7 dan 8 persetanse kadar air mencapai di atas 40\% dimana tanah dapat dikategorikan tanah lembab, sedangkan pada sensor 3, 6 dan 9 persentase kadar air di bawah 30\% dimana tanah dikategorikan tanah kering. Nilai antar sensor tidak homogen dalam lingkup area tersebut, namun menunjukkan kecenderungan yang seragam dari lokasi terdekatnya.

\section{E. Pengujian Sistem Peringatan}

Pengujian ini bertujuan untuk memastikan sistem peringatan pada saat tanah mengalami kekurangan atau kelebihan air. Pesan peringatan tanah kekurangan air jika nilai kelembapan tanah antara 0-300 dan peringatan kelebihan air untuk kelembapan antara 601-900.

Sistem pemantauan kelembapan tanah berfungsi dengan baik yang ditunjukkan dengan adanya pesan peringatan jika nilai kelembapan tanah antara 0-300 pada tanah kering (Gambar 12a). Apabila pesan ini keluar, maka pengguna harus segera menyiram tanaman dan tanah hingga nilai kelembapan air menjadi 301-600. Pesan peringatan kelebihan air jika nilai kelembapan tanah antara 601-900 dimana tanah tersebut termasuk tanah basah (Gambar 12b). Pengguna harus segera menghentikan proses penyiraman apabila pesan ini muncul pada aplikasi.

Sistem pemantau kelembapan tanah menggunakan multi sensor dan platform OpeMTC ini telah dapat melakukan pemantauan kadar air tanah di suatu area berdasarkan data kelembapan tanah. Pesan peringatan dapat dilanjutkan dengan sistem kontrol penyiraman seperti halnya dalam [8] untuk pengontrolan irigasi lahan pertanian. Lebih lanjut, data hasil pemantauan kadar air tanah ini dapat disimpan dan diaplikasikan dalam manajemen tata taman atau pertanian seperti halnya dalam [9]-[11].

\section{KESIMPULAN}

Sistem pemantau kelembapan tanah menggunakan Arduino yang terhubung dengan platform OpenMTC dan komunikasi protokol ZigBee dapat berfungsi efektif untuk mendeteksi kelembapan tanah secara akurat. Jarak area maksimum yang dimonitor adalah $25 \mathrm{~m}$ untuk kondisi ada penghalang dan 50 meter pada kondisi tidak ada penghalang dengan kedalaman tiap sensor $3 \mathrm{~cm}$.

\section{UCAPAN TERIMA KASIH}

Penulis berterima kasih kepada Telkom University atas dukungan moril maupun material dalam pelaksanaan penelitian dan publikasi ini.

\section{DAFTAR Pustaka}

[1] O. H. Jacobsen and P. Schjonning, “A Laboratory Calibration of Time Domain Reflectometry for Soil Water Measurement Including Effects of Bulk Density and Texture," Journal of Hydrology, vol. 151, no. 2-4, pp. 147-157, 1993.

[2] H. Karl and A. Willig, Protocols and Architectures for Wireless Sensor Networks. West Sussex: John Wiley \& Sons, 2005.

[3] S. Farahani, Zigbee Wireless Network and Transceivers, 1st ed. Newnes, 2008.

[4] J. Zheng and M. J. Lee, "Will IEEE 802.15.4 Make Ubiquitous Networking a Reality?: A Discussion on a Potential Low Power, Low Bit Rate Standard," IEEE Communications Magazine, vol. 42, no. 6, pp. 140-146, 2004.

[5] A. M. Sadeghioon, N. Metje, D. N. Chapman, and C. J. Anthony, "SmartPipes: Smart Wireless Sensor Networks for Leak Detection in Water Pipelines," Journal of Sensor and Actuator Networks, vol. 3, no. 1, pp. 64-78, 2014.

[6] M. Abdurohman, A. Sasongko, and A. Herutomo, "M2M Middleware Based on OpenMTC Platform for Enabling Smart Cities Solution,” in Smart City 360, pp. 239-249, Springer, Cham, 2016.

[7] P. A. L. Besari, M. Abdurohman and A. Rakhmatsyah, "Application of M2M to Detect the Air Pollution," in 2015 3rd International Conference on Information and Communication Technology (ICoICT), 2015, Nusa Dua, Indonesia, pp. 304-309.

[8] G. V. Satyanarayana and S. D. Mazaruddin, "Wireless Sensor Based Remote Monitoring System for Agriculture using ZigBee and GPS," in Conference on Advances in Communication and Control Systems, vol. 3, pp. 237-241, 2013. 
[9] F. TongKe, "Smart Agriculture Based on Cloud Computing and IOT," Journal of Convergence Information Technology, vol. 8, no. 2, 2013.

[10] P. J. Nachankar, M. G. Somani, D. M. Singh, and S. N. Katkar, "IOT in Agriculture," International Research Journal of Engineering and Technology, vol. 5, no. 4, pp. 592-596, 2018.

[11] M. Stoces, J. Vanek, J. Masner, and J. Pavlík, "Internet of Things (IoT) in Agriculture-Selected
Aspects,” Agris on-line Papers in Economics and Informatics, vol. 8, no. 1, pp. 83-88, 2016.

[12] H. Karamina, W. Fikrinda, and A. T. Murti, "Kompleksitas Pengaruh Temperatur dan Kelembaban Tanah terhadap Nilai pH Tanah di Perkebunan Jambu Biji Varietas Kristal (Psidium Guajava 1.) Bumiaji, Kota Batu,” Jurnal Kultivasi, vol. 16, no. 3, pp. 430-434, 2017. 